\title{
Construction of suppressor of cytokine signaling 2 (SOCS2) adenoviral overexpression vector and its impact on growth hormone- induced lipolysis in swine primary adipocytes
}

\author{
H.L. Yang*, J. Yan*, M. Feng*, X. Tan*, G.Y. Yan*, L. Gan* and C. Sun \\ College of Animal Science and Technology, Northwest A\&F University, \\ Yangling, Shaanxi, China \\ *These authors contributed equally to this study. \\ Corresponding author: C. Sun \\ E-mail: sunchao2775@163.com
}

Genet. Mol. Res. 12 (2): 1283-1293 (2013)

Received June 28, 2012

Accepted October 3, 2012

Published January 9, 2013

DOI http://dx.doi.org/10.4238/2013.January.9.2

\begin{abstract}
We investigated the effect of overexpression suppressor of cytokine signaling 2 (SOCS2) on lipolysis in swine primary adipocytes (pAd) induced by growth hormone $(\mathrm{GH})$. We constructed pAd-SOCS2 adenoviral overexpression vectors to infect HEK293 cells for virus packaging and propagation. Cultured swine primary adipocytes were infected with virus particles; after $48 \mathrm{~h}$ the infected adipocytes were treated with $500 \mathrm{ng} \mathrm{GH} / \mathrm{mL}$ in the growth medium. Lipometabolismrelated gene expressions were detected at $0,0.25,0.5,1,2$, and $4 \mathrm{~h}$, by measuring mRNA and protein levels. The pAd-SOCS2 overexpression vector was successfully constructed and the concentration of titrated virus was $1.2 \times 10^{9} \mathrm{PFU} / \mathrm{mL}$. We found that virus infection significantly increased SOCS2 mRNA and protein levels in swine primary adipocytes. Overexpression of SOCS2 significantly inhibited the increase in fatty acid synthase, adipose triglyceride lipase mRNA, and protein expression at $0.5 \mathrm{~h}$. However, after $0.5 \mathrm{~h}$, this inhibition was not significant. We concluded that overexpression of SOCS2 inhibited the
\end{abstract}


increase in lipolysis induced by GH in swine primary adipocytes; this could provide a basis for studies of lipometabolism.

Key words: Swine; SOCS2; Overexpression adenoviral vector; Primary adipocytes; Lipolysis

\section{INTRODUCTION}

As an important member of the overexpression suppressor of cytokine signaling (SOCS) family, SOCS2 has a broad role in many physiological activities. Ouyang et al. (2006) used SOCS2 plasmid vectors to transfect C2C12 mesenchymal precursor cells and investigated whether SOCS2 could enhance cell proliferation and survival and inhibit spontaneous myotube formation. Zhang et al. (2010) demonstrated that SOCS2 might play an important role in the immune defense of invertebrates by cloning the full-length cDNA of SOCS2 from Eriocheir sinensis and analyzing the developmental status of E. sinensis SOCS2. On the other hand, SOCS2 can regulate fat deposition and fat metabolism, but related research is lacking and regulatory mechanisms are unclear. The basal expression of SOCS2 in adipocytes has been found to be low. Usually, SOCS2 expresses at high levels when induced by growth hormone (GH) (Tollet-Egnell et al., 1999; Johansen et al., 2003; Berryman et al., 2004; Pasarica et al., 2007; Plockinger and Reuter, 2008).

$\mathrm{GH}$, which is a peptide hormone secreted by the anterior pituitary, combines with GH receptor on the cell surface in target tissue and regulates growth. Specifically, GH could activate the hormone-sensitive lipase in subcutaneous adipose tissue to promote lipolysis and increase fatty acids in the blood. This function has been shown to be more effective in visceral fat (Ng et al., 2000; Sun et al., 2012a). However, SOCS2 is an important negative factor of cytokine signal transduction, as growth is inhibited in $\mathrm{SOCS2}^{-/-}$mice (Metcalf et al., 2000). Besides, SOCS2 overexpression in mice leads to a significantly bigger size than in wild-type ones (Greenhalgh et al., 2002). All these findings suggested that SOCS2 might regulate the GH signal pathway 2 -fold, but its biochemical mechanism is yet unknown. In this study, we overexpressed the SOCS2 gene in swine primary adipocytes (pAd) and detected the lipometabolism-related genes by real-time PCR (RT-PCR) and Western blotting for a preliminary look at the role of SOCS2 in the regulation of lipolysis in swine pAd induced by GH. A theoretical basis for the regulatory mechanism of SOCS2 in the GH signaling pathway is discussed.

\section{MATERIAL AND METHODS}

\section{Main materials}

Three-day-old Large White pigs were purchased from Shaanxi Yangling Guangming farms; Escherichia coli DH5 $\alpha$ was kept in our laboratory; pAdTrack-CMV, pAdEasy-1 plasmid and E. coli BJ5183 strain were donated by the College of Animal Science and Technology, Northwest A\&F University, Pig Fat Deposition and Muscle Development Laboratory; human embryonic kidney cell line (HEK293) was purchased from the cell resource center of the Chinese Academy of Sciences.

Reagents and antibody, Dulbecco's modified Eagle's medium (DMEM/F12) and type 
I collagenase were purchased from Gibco (USA). Fetal bovine serum (FBS) was purchased from Hyclone (USA). Lipofectamine 2000 was purchased from Invitrogen (USA). Restriction enzymes PmeI and PacI were purchased from New England Biolabs (USA). RNAiso Plus was purchased from Takara (Dalian, China). The RevertAid First Strand cDNA Synthesis kit and ExTaq DNA Polymerase were purchased from Fermentas (USA). Antibodies were purchased from Santa Cruz (USA).

\section{Cloning of SOCS 2 and recombination of overexpression vector}

Before cloning, cDNA was first synthesized. Next, based on the porcine SOCS2 gene sequence (GenBank ID: NM_007706.3), the sequence tagged site and a pair of primers (SOCS2-BglII-F and SOCS2-Flag-X XhoI-R) were designed to amplify the region by PCR. Later, the products were visualized following electrophoresis on a $1 \%$ ethidium bromide-stained agarose gel, and the unique band was cut out for fragment recovery and storage at $-20^{\circ} \mathrm{C}$ for reuse (Bioflux Company).

pAdTrack-CMV plasmid and the SOCS2 gene were double-digested with the enzymes $B g l I I$ and $X h o I$, then the double-digested products were recycled and connected with T4 ligase at $16^{\circ} \mathrm{C}$ overnight. The scale of the SOCS2 gene concentration and of the pAdTrack-CMV plasmid concentration was 3 to 5 . After the transformation, screening and identification by PCR and double-digestion, pAdTrack-CMV-SOCS2 was constructed and available for linearization with the enzyme PmeI. The linear fragments precipitated by ethanol were transformed into BJ5183 competent cells with pAdEasy-1 for homologous recombination. After screening on LB solid culture plates with $100 \mu \mathrm{g} / \mathrm{mL}$ kanamycin and identification, pAd-SOCS2 was ready and stored at $-20^{\circ} \mathrm{C}$ (Table 1$)$.

\begin{tabular}{|c|c|c|c|}
\hline Primer name & Primer sequence $\left(5^{\prime}-3^{\prime}\right)$ & Accession No. & $\operatorname{Tm}\left({ }^{\circ} \mathrm{C}\right)$ \\
\hline SOCS2- BglII-F & GCAGATCTATGACCCTGCGGTGCCTGG & NM_001097461.1 & 57.0 \\
\hline SOCS2-Flag-XhoI-R & $\begin{array}{l}\text { GCCTCGAGTTACTTATCGTCGTCATCCT } \\
\text { TGTAATCTACCTGGAATTTATATTCTT }\end{array}$ & & \\
\hline SOCS2-F & ACTAACCTGCGGATTGAG & NM_001097461.1 & 53.8 \\
\hline SOCS2-R & CAGAGTGGGTGCTGATGT & & \\
\hline$F A S-\mathrm{F}$ & AGCCTAACTCCTCGCTGCAAT & NM_001099930.1 & 57.8 \\
\hline$F A S-\mathrm{R}$ & TCCTTGGAACCGTCTGTGTTC & & \\
\hline$A T G L-\mathrm{F}$ & СCTCATTCCACCTGCTCTCC & EU373817.1 & 59.3 \\
\hline$A T G L-\mathrm{R}$ & GTGATGGTGCTCTTGAGTTCGT & & \\
\hline
\end{tabular}

$\mathrm{Tm}=$ melting temperature; $\underline{\mathrm{AGATCT}}=B g l \mathrm{II} ; \underline{\mathrm{CTCGAG}}=X h o \mathrm{I}$.

\section{pAd-SOCS2 package, propagation and virus titer determination}

HEK293 cells were grown up to $70 \%$ confluence and were then transfected with adenovirus vectors of pAd-SOCS2, which were expanded and linearized with PacI. After $24 \mathrm{~h}$, cells were checked for green fluorescent protein (GFP) expression, and 8-10 days after the transfection, they were examined for cytopathic effect (CPE). Cells with CPE were scraped into vials for freezing in liquid nitrogen and thawing at $37^{\circ} \mathrm{C}, 5$ times, and the vials were then centrifuged for $5 \mathrm{~min}$ at 12,000 rpm. Supernatant liquid containing the virus Ad-SOCS2 was collected for subsequent transfection (when cells reached $90 \%$ confluence). At $24 \mathrm{~h}$ after trans- 
fection, cell morphology and GFP expression were observed. After repeating this procedure 3 times, the virus titer was detected by the $\mathrm{TCID}_{50}$ method and reached $1.2 \times 10^{9} \mathrm{PFU} / \mathrm{mL}$.

\section{Culture of primary adipocytes and infection with Ad-SOCS2}

Subcutaneous fat from the neck and back of 3-day-old Large White pigs was harvested and washed with phosphate-buffered saline (PBS) 3 times. The samples were then sheared to $1 \mathrm{~mm}^{3}$ and digested with collagenase I at $37^{\circ} \mathrm{C}$ for $1 \mathrm{~h}$. Cells were filtered through a micron nylon membrane to remove tissue debris and concentrated by centrifugation. Isolated cell pellets were suspended in DMEM/F12. Finally, cells were seeded on culture plates at a density of $4.0 \times 10^{4}$ cells $/ \mathrm{cm}^{2}$ and grown in DMEM/F12, supplemented with $10 \%(\mathrm{v} / \mathrm{v}) \mathrm{FBS}$ and $100 \mathrm{U}$ mycillin, at $37^{\circ} \mathrm{C}$ in a humidified atmosphere containing $5 \% \mathrm{CO}_{2}$. The medium was changed every other day. The cells were infected with Ad-SOCS2 to choose the optimal multiplicity of infection (MOI). When $70 \%$ confluence was reached, the medium was changed to serum-free overnight, and the cells were induced with $500 \mathrm{ng} / \mathrm{mL}$ GH after $48 \mathrm{~h}$. Cells were harvested at $0,0.25,0.5,1,2$, and $4 \mathrm{~h}$ for extraction of RNA and protein.

\section{RT-PCR}

Primers of fatty acid synthase (FAS), adipose triglyceride lipase (ATGL) and SOCS2 were designed by the Primer Premier 5.0 software for RT-PCR. RT-PCR amplifications were carried out on a Bio-Rad iQ5 (Hercules, CA, USA) by SYBR Premix Ex TaqTMII chemistry detection under amplification conditions. The $2^{-\Delta \Lambda C t}$ method was used for PCR data analysis. $\Delta \Delta \mathrm{Ct}=(\mathrm{Ct}$, target gene in treated group - $\mathrm{Ct}$, reference gene in treated group $)$ - $(\mathrm{Ct}$, target gene in control group - $\mathrm{Ct}$, reference gene in control group).

\section{Western blotting}

Cells were harvested and lysed with $200 \mu \mathrm{L}$ lysis buffer RIPA (20 mM Tris, $\mathrm{pH} 7.5,5$ mM EDTA, $150 \mathrm{mM} \mathrm{NaCl}, 1 \%$ Nonidet P-40, $0.1 \mathrm{mM} \mathrm{Na}_{3} \mathrm{VO}_{4}, 1 \mathrm{mM} \mathrm{NaF}, 10 \mathrm{mM}$ sodium $\beta$-glycerophosphate, $0.1 \mathrm{mM}$ phenylmethylsulfonyl fluoride, $1 \mu \mathrm{g} / \mathrm{mL}$ leupeptin, $10 \mu \mathrm{g} / \mathrm{mL}$ aprotinin) for $30 \mathrm{~min}$ at $4^{\circ} \mathrm{C}$. After centrifugation at $12,000 \mathrm{~g}$ for $10 \mathrm{~min}$ at $4^{\circ} \mathrm{C}$, the supernatants were removed and their protein concentrations were determined by the bicinchoninic acid method. Total protein extracts were separated by $12 \%$ SDS-polyacrylamide gel electrophoresis and transferred to a polyvinylidene membrane $(60 \mathrm{~V}$ for $4 \mathrm{~h})$. The membranes were blocked with 5\% nonfat milk in TBST (Tris-buffered saline containing $0.1 \%$ Tween 20) at room temperature for $2 \mathrm{~h}$, and probed overnight with unique (Santa Cruz) primary antibodies at $4^{\circ} \mathrm{C}$. After washing with TBST, the membranes were probed with secondary antibodies (Santa Cruz) at room temperature for $1.5 \mathrm{~h}$. Blots were visualized with a chemiluminescence reagent (Millipore, USA) and an imaging system (BioRad).

\section{Statistical analysis}

The SPSS 13.0 statistics software package was used for one-way ANOVA. Data are reported as means \pm standard error. Differences were considered to be statistically significantly at $\mathrm{P}<0.05$ or $\mathrm{P}<0.01$. 


\section{RESULTS}

\section{Cloning of the SOCS2 gene}

We extracted RNA from pig subcutaneous adipose tissue for cDNA synthesis by reverse transcription. We then used cDNA to amplify the SOCS2 gene by RT-PCR and ligate it to the pMd-18T vector for the construction of pMd-18T-SOCS2. After sequencing, pMd18T-SOCS2 was used as the template to amplify the SOCS2 gene fragment with a tag and restriction sites and identified by electrophoresis, as described below. Figure 1A shows the representative gel picture of SOCS2 (650 bp) amplification by PCR. The purified SOCS2 gene PCR product is shown in Figure 1B. The SOCS2 fragments amplified had a size of $650 \mathrm{bp}$, which matched the theoretical size.

\section{A}
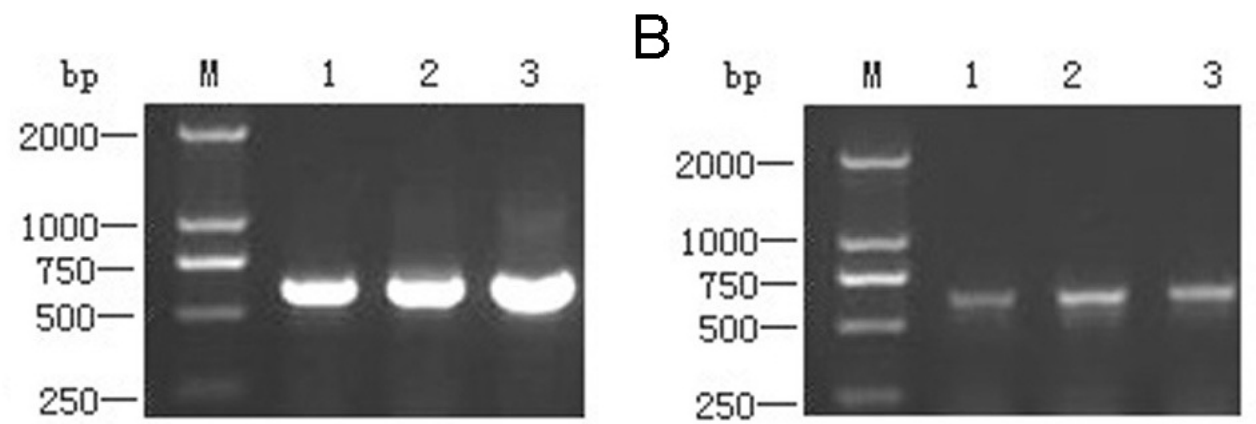

Figure 1. SOCS2 gene electrophoresis analysis of PCR product and gel recovery product. A. Representative gel picture of SOCS2 (650 bp) by PCR; B. Purified PCR product. Lane $M=$ marker 2000; lanes 1 to $3=$ three repeats.

\section{pAdTrack-CMV-SOCS2 and Ad-SOCS2}

The pAdTrack-CMV vector and the SOCS2 target gene were digested with BglII and $X h o I$ restriction enzymes. Then, the products were recycled for connecting with T4 ligase at $16^{\circ} \mathrm{C}$ overnight. After the transformation, screening and identification by PCR and double-digestion, the positive monoclonal were identified. Figure 2A shows the picked positive monoclonal of pAdTrack-CMV-SOCS2. It was verified by PCR (Figure 2B) and double-enzyme cleavage (Figure 2C), where the visible size was $650 \mathrm{bp}$ and consistent with the theoretical size. pAdTrack-CMV-SOCS2 was linearized with PmeI restriction enzyme and transformed into the BJ5183 competent cells containing pAd-Easy-1 for homologous recombination on LB plates incubated at $37^{\circ} \mathrm{C}$ for $16-20 \mathrm{~h}$. Figure $2 \mathrm{D}$ shows the positive monoclonal of Ad-SOCS2. PCR identification is shown in Figure 2E. We used PacI restriction enzyme to digest and release a $4.5-\mathrm{kb}$ fragment, shown in Figure 2F. Verified by sequencing, the homology of the target SOCS2 gene in the recombinant plasmid and deposited in GenBank (GenBank accession No. NM-007706.3) was found to be $100 \%$, which showed that Ad-SOCS2 was built successfully. 


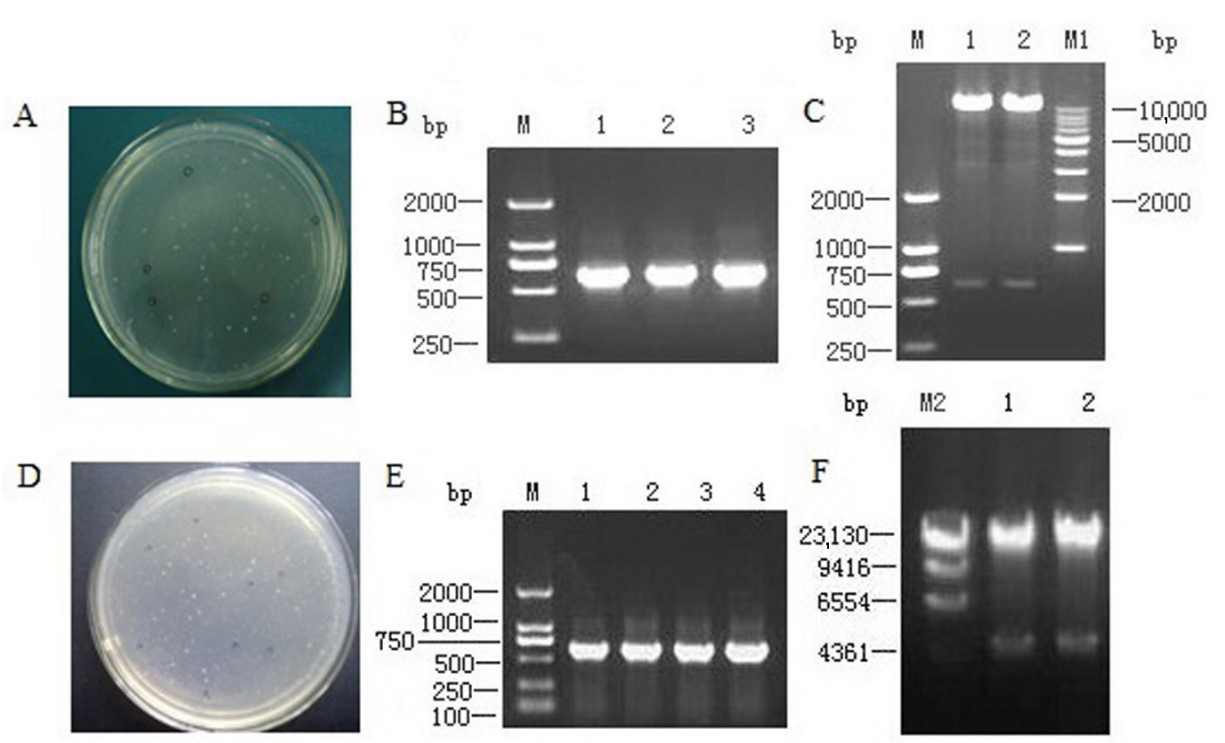

Figure 2. Identification of pAdTrack-CMV-SOCS2 and recombinant adenovirus overexpression vector Ad-SOCS2. Lane $M=$ marker 2000; lane $M 1=1-\mathrm{kb}$ marker; lane $M 2=\lambda$ HindIII marker; A. screening the positive monoclonal of pAdTrack-CMV-SOCS2; B. pAdTrack-CMV-SOCS2 was verified by PCR; C. pAdTrack-CMV-SOCS2 verified by double-enzyme cleavage; D. after homologous recombination, the positive monoclonal of Ad-SOCS2 is picked; E. F. Ad-SOCS2 verified by PCR and double-enzyme cleavage, respectively. Lanes 1-3 (A), lanes 1 and 2 (C, F), lanes 1-4 $(\mathrm{E})=$ three, two and four repeats, respectively.

\section{Packaging and propagation of Ad-SOCS2}

Photographs of HEK293 cells infected with the adenoviral vector containing AdSOCS2 were taken at $24 \mathrm{~h}$ when GFP could be first observed (Figure 3A).The fluorescence was observed as bundles for 7 days (Figure 3B), and after 10 days, most cells showed the CPE phenomenon, which meant that cells could be harvested for virus that were used for packaging (Figure 3C). Figure 3D, E and F show the progress of virus packaging; GFP in Figure 3D showed that almost $60 \%$ of the cells were infected in the first multiplication of virus, and this ratio increased more than $90 \%$ in the third multiplication (Figure 3E). After $24 \mathrm{~h}$, the expression of cell GFP was apparent when the cells turned round and wrinkled-like, as shown in Figure $3 \mathrm{~F}$, and it was then appropriate to harvest the virus. The virus particles obtained had a titer of $1.2 \times 10^{9} \mathrm{PFU} / \mathrm{mL}$.

\section{MOI of Ad-SOCS2 virus liquid}

Figure 4A and B show the mRNA and protein expressions of SOCS2 in swine primary adipocyte infected with Ad-SOCS2 at different MOI. Expression of SOCS2 in infected adipocytes was significantly higher than in the uninfected control group $(\mathrm{P}<0.01)$. SOCS2 in adipocytes infected with MOI 20 and 25 expressed nearly the same levels, but expression in both was significantly higher than that in cells infected with MOI 15. Figure 4C and D show that mRNA and protein expression of SOCS2 in adipocytes induced with GH was significantly higher compared with Ad-null groups $(\mathrm{P}<0.01)$. As a result, MOI 20 was the most suitable for further experiments. 

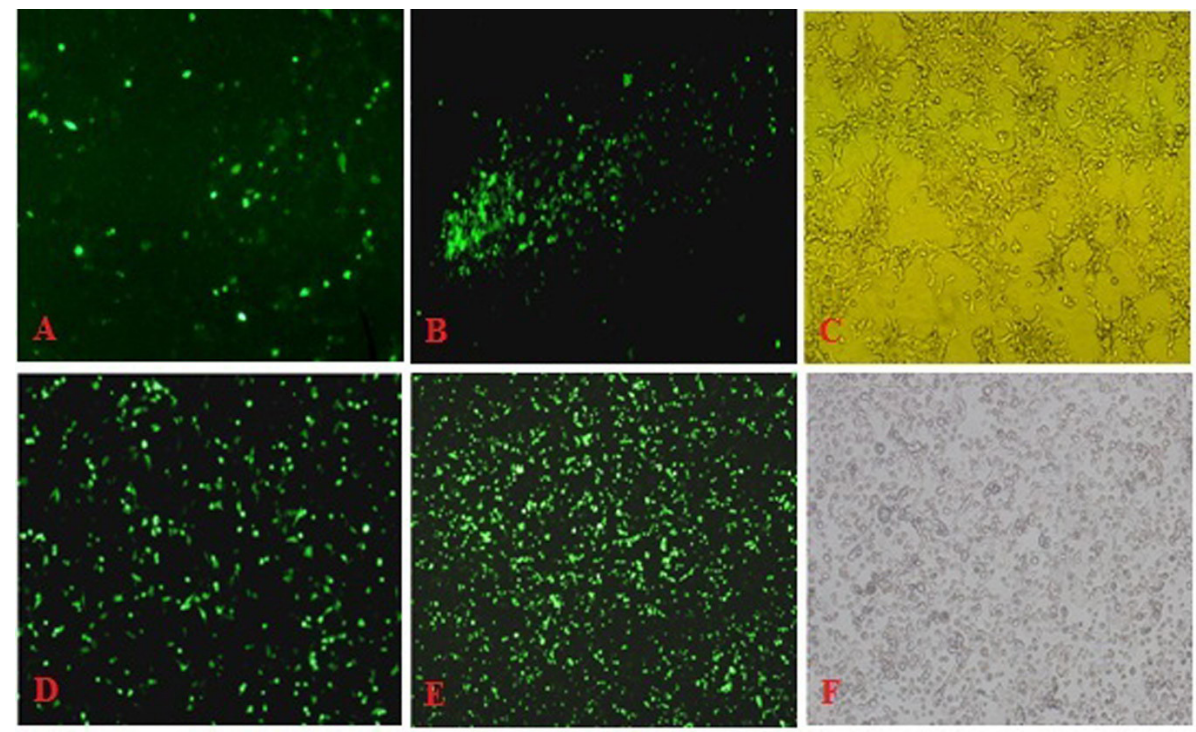

Figure 3. Ad-SOCS2 packaging and multiplication (100X); HEK293 cells were infected with Ad-null or AdSOCS2. A. HEK293 cells infected with Ad-SOCS2 for 24 h; B. HEK293 cells infected with Ad-SOCS2 for 7 days; C. HEK293 cells infected with Ad-SOCS2 for 10 days and then harvested; D. the first time multiplication of Ad-SOCS2 virus; E. the third time multiplication of Ad-SOCS2 virus; F. HEK293 cells are an apparent cytopathic effect phenomenon.

A

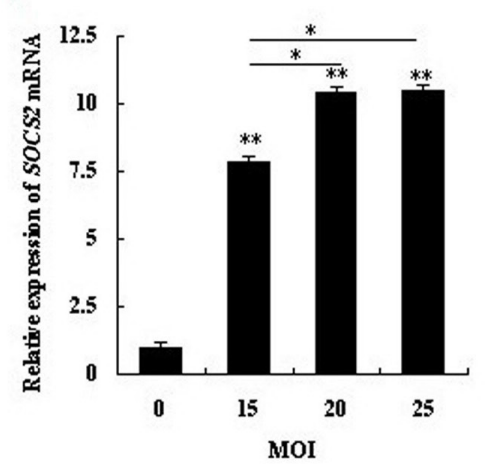

B

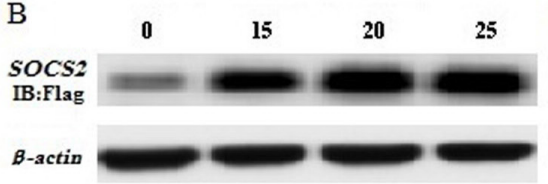

C

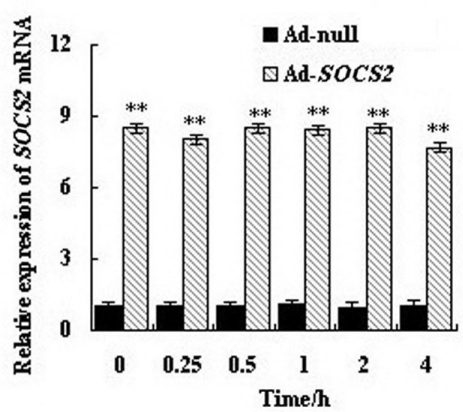

$\mathrm{D}$

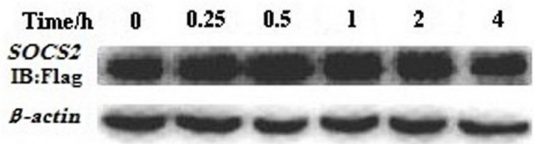

Figure 4. Measure of Ad-SOCS2 multiplicity of infection (MOI) values and the effect of Ad-SOCS2 on swine primary adipocyte. *Significant difference $(\mathrm{P}<0.05)$. **Significant difference $(\mathrm{P}<0.01)$. A. SOCS2 mRNA expressions in different MOI values in swine primary adipocyte; B. SOCS2 protein expressions in different MOI values in swine primary adipocyte; C. overexpressions of SOCS2 could obviously increase the SOCS2 mRNA expression; D. overexpressions of SOCS2 could obviously increase the SOCS2 protein expression. 


\section{Expressions of key enzymes in fat metabolism}

First, we used $500 \mathrm{ng} / \mathrm{mL}$ GH to treat adipocytes for $0,0.25,0.5,1,2$, and $4 \mathrm{~h}$. PBS groups were as controls, which clarified the effect of GH on primary adipocytes. The cells were collected and expression of $F A S$ and $A T G L$ was determined by RT-PCR and Western blotting. Compared with control groups, $500 \mathrm{ng} / \mathrm{mL}$ GH increased $F A S$ mRNA expression in primary adipose cells, and it was significantly higher within $0.5 \mathrm{~h}$, but decreased afterwards, with a significant decrease $4 \mathrm{~h}$ later (Figure 5A). The same situation occurred with gene ATGL that is shown in Figure 5B. At the same, we determined the protein expression of these two genes, which showed the same trend with mRNA expression (Figure 5C, D, E, and F). These results indicated that $500 \mathrm{ng} / \mathrm{mL}$ GH could stimulate $F A S$ expressions during an early stage (0.25-1 h), but with time, mRNA and protein expressions were notably reduced. At the same time, GH increased $A T G L$ expression, both mRNA and protein, but the inhibitory action decreased with time.

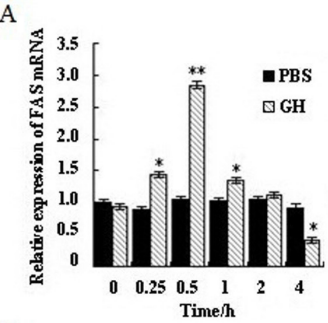

$\mathrm{C}$

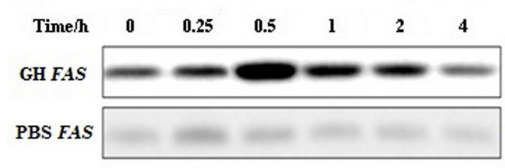

E

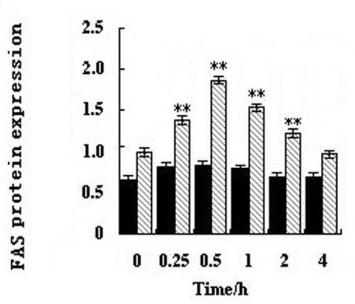

B

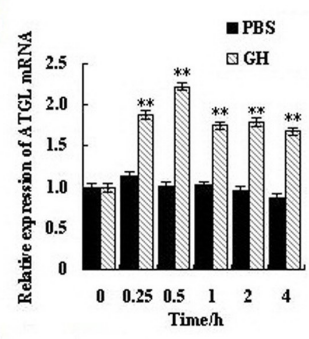

$\mathrm{D}$

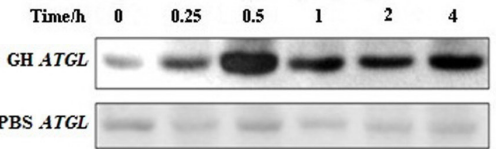

F

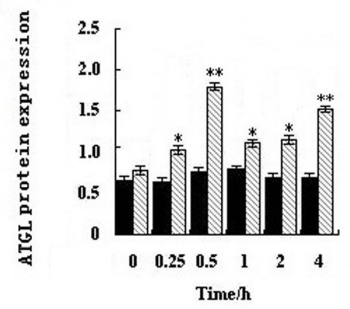

Figure 5. Growth hormone $(\mathrm{GH})$ induced fatty acid synthase $(F A S)$ and adipose triglyceride lipase $(A T G L)$ expressions. A. and B. FAS and $A T G L$ mRNA expressions in primary adipose cells; C. D. E. F. FAS and ATGL protein expressions in primary adipose cells. $\mathrm{PBS}=$ phosphate-buffered saline. ${ }^{*}$ Significant difference $(\mathrm{P}<0.05)$. $* *$ Significant difference $(\mathrm{P}<0.01)$.

Next the swine primary adipocytes were infected with pAd-SOCS2 for $48 \mathrm{~h}$, Ad-null infection served as control. The adipocytes were then treated with $500 \mathrm{ng} / \mathrm{mL}$ GH for $0.25,0.5$, 1,2 , and $4 \mathrm{~h}$ after serum starvation overnight. By detecting the expressions of $F A S$ and $A T G L$ by RT-PCR and Western blotting, we found that overexpression of SOCS2 could inhibit the increase in mRNA expression of both genes induced by $\mathrm{GH}$ at $0.25 \mathrm{~h}(\mathrm{P}<0.05)$ and $0.5 \mathrm{~h}(\mathrm{P}<0.01)$ (Figure 6A, B). In Figure 6C, D, E, and F, we see that overexpression of SOCS2 significantly inhibited GH-induced $F A S$ and $A T G L$ protein expression, which was consistent with mRNA detection. 
A

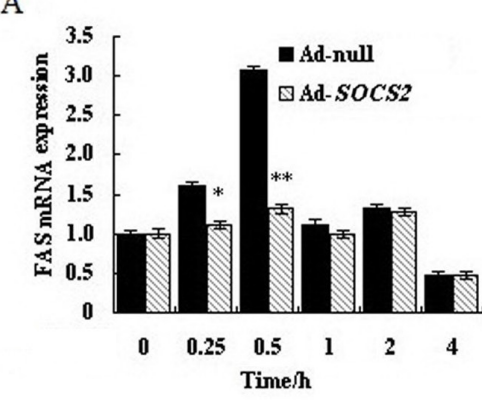

$\begin{array}{llllllll}C & \text { Time/h } & 0 & 0.25 & 0.5 & 1 & 2 & 4\end{array}$

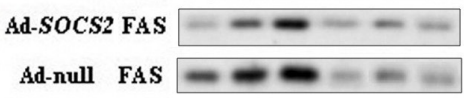

$\mathrm{E}$

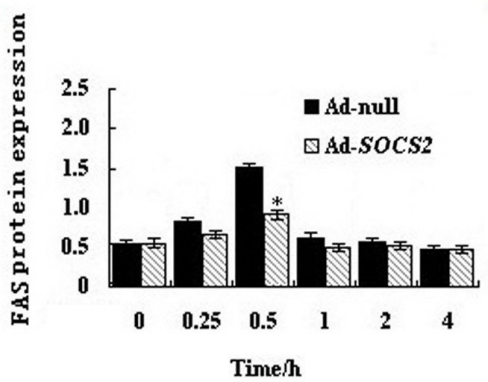

B

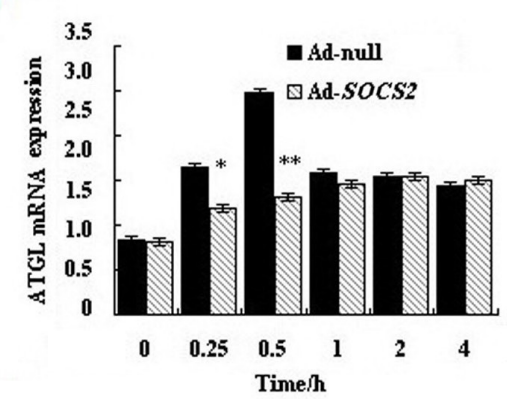

$\begin{array}{llllllll}\mathrm{D} & \text { Time/h } & 0 & 0.25 & 0.5 & 1 & 2 & 4\end{array}$

Ad-SOCS2 ATGL

Ad-null ATGL $-\div-\div-\div$

$\mathrm{F} g$

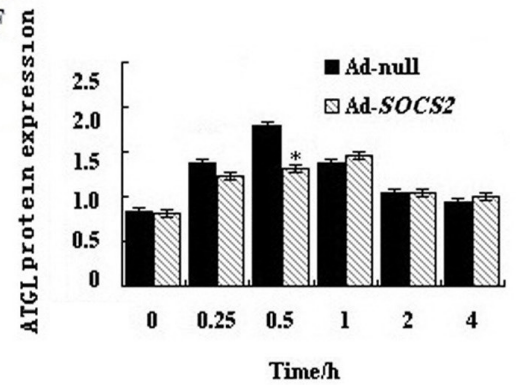

Figure 6. Overexpression of SOCS2 could inhibit growth hormone (GH)-induced fatty acid synthase $(F A S)$ and adipose triglyceride lipase ( $A T G L$ ) expressions. A. and B. FAS and $A T G L$ mRNA expressions in primary adipose cells; C. D. E. F. FAS and ATGL protein expressions in primary adipose cells. * Significant difference $(\mathrm{P}<0.05)$. $* *$ Significant difference $(\mathrm{P}<0.01)$.

\section{DISCUSSION}

Research on lipid metabolism is meaningful, as it is closely related to many diseases such as obesity, hepatic steatosis, coronary heart disease, and so on. With regard to the current study, it had already been found that GH significantly promotes lipolysis by reducing glucose transport and lipid synthesis, and repressing the transcription of FAS in both in vivo and in vitro experiments (Louveau and Gondret, 2004). It also has been reported that GH induces a high level of expression in the SOCS family, especially SOCS2, a stable longtime high level expression (Paul et al., 2000; Greenhalgh et al., 2005). Flores-Morales et al. (2001) and RicoBautista et al. (2004) confirmed this; they also found that GH could induce a stable high level of SOCS2 expression and that other SOCS family members just showed a little increase in expression, which gradually weakened. Further studies have shown that SOCS2 is a negative regulator of GH signaling, resulting in inhibition of intestinal epithelial cell proliferation, which is induced by GH and IGF-1 (Miller et al., 2004), the negative action of estrogen on GH signaling, which is caused by an upregulation of SOCS2 (Leung et al., 2003), and the blocking of GH-dependent inhibition of neural stem cell differentiation (Turnley, 2005). It is also known that glucocorticoids have negative effects on somatic growth and enhance GH-induced SOCS2 
expression in primary hepatocytes (Tollet-Egnell et al., 1999; Sun et al., 2012b), suggesting SOCS2 as the mediator of the negative effects of glucocorticoids on GH action.

All these results are consistent with our study that GH improved expression of SOCS2 steady (Figure 4C and D), while the SOCS2 gene negative feedback regulated GH signaling pathway at the same time.

At present, the specific role of both the interaction between the SOCS2 gene and the GH signaling pathway and its mechanism of fat metabolism are poorly researched. To further investigate the mechanism of SOCS2 on GH regulation of fat cell lipid metabolism, we constructed an overexpression vector with pAd-SOCS2 to study the impact of GH-induced fat metabolism. To facilitate a follow-up test, a flag tag sequence was added in the downstream primer of amplified SOCS2 CDS. HEK293 cell density was required to be more stringent when pAd-SOCS2 was packaged. We found that the HEK293 cells showed a higher infection efficiency when confluence was $60-70 \%$. The degree of cell confluence should reach $90 \%$ when the virus is propagated for more efficient infection; the good state of cells was the main factors in the entire packaging and propagation process. The final virus titer was $1.2 \times 10^{9}$ $\mathrm{PFU} / \mathrm{mL}$.

Specifically, mRNA and protein expression of FAS and ATGL in swine primary adipocytes was significantly increased within $0.5 \mathrm{~h}$ after treatment with $\mathrm{GH}$, which was in line with the research of Stewart et al. (2004) who showed that GH induced the expression of FAS in 3T3-L1 cells. However, another previous study showed that expression of FAS was not affected with GH treatment at either the mRNA or protein level (Kawai et al., 2007). This difference may be due to different cell types or detection times. Further results indicated that the SOCS2 gene may regulate fat metabolism through the GH signal pathway, because overexpression of the SOCS2 inhibited the expression of $A T G L$ and FAS, which should have been increased by the treatment with GH. However, the specific mechanism of this inhibition is still uncertain.

\section{ACKNOWLEDGMENTS}

Research supported by the National Nature Science Foundation of China (\#31172185) and the Science and Technology Program of Shaanxi Province (\#2012NKC01-13).

\section{REFERENCES}

Berryman DE, List EO, Coschigano KT, Behar K, et al. (2004). Comparing adiposity profiles in three mouse models with altered GH signaling. Growth Horm. IGF Res. 14: 309-318.

Flores-Morales A, Fernandez L, Rico-Bautista E, Umana A, et al. (2001). Endoplasmic reticulum stress prolongs GHinduced Janus kinase (JAK2)/signal transducer and activator of transcription (STAT5) signaling pathway. Mol. Endocrinol. 15: 1471-1483.

Greenhalgh CJ, Metcalf D, Thaus AL, Corbin JE, et al. (2002). Biological evidence that SOCS-2 can act either as an enhancer or suppressor of growth hormone signaling. J. Biol. Chem. 277: 40181-40184.

Greenhalgh CJ, Rico-Bautista E, Lorentzon M, Thaus AL, et al. (2005). SOCS2 negatively regulates growth hormone action in vitro and in vivo. J. Clin. Invest. 115: 397-406.

Johansen T, Richelsen B, Hansen HS, Din N, et al. (2003). Growth hormone-mediated breakdown of body fat: effects of $\mathrm{GH}$ on lipases in adipose tissue and skeletal muscle of old rats fed different diets. Horm. Metab. Res. 35: 243-250.

Kawai M, Namba N, Mushiake S, Etani Y, et al. (2007). Growth hormone stimulates adipogenesis of 3T3-L1 cells through activation of the Stat5A/5B-PPARgamma pathway. J. Mol. Endocrinol. 38: 19-34.

Leung KC, Doyle N, Ballesteros M, Sjogren K, et al. (2003). Estrogen inhibits GH signaling by suppressing GH-induced JAK2 phosphorylation, an effect mediated by SOCS-2. Proc. Natl. Acad. Sci. U. S. A. 100: 1016-1021. 
Louveau I and Gondret F (2004). Regulation of development and metabolism of adipose tissue by growth hormone and the insulin-like growth factor system. Domest. Anim. Endocrinol. 27: 241-255.

Metcalf D, Greenhalgh CJ, Viney E, Willson TA, et al. (2000). Gigantism in mice lacking suppressor of cytokine signalling-2. Nature 405: 1069-1073.

Miller ME, Michaylira CZ, Simmons JG, Ney DM, et al. (2004). Suppressor of cytokine signaling-2: a growth hormoneinducible inhibitor of intestinal epithelial cell proliferation. Gastroenterology 127: 570-581.

Ng FM, Jiang WJ, Gianello R, Pitt S, et al. (2000). Molecular and cellular actions of a structural domain of human growth hormone (AOD9401) on lipid metabolism in Zucker fatty rats. J. Mol. Endocrinol. 25: 287-298.

Ouyang X, Fujimoto M, Nakagawa R, Serada S, et al. (2006). SOCS-2 interferes with myotube formation and potentiates osteoblast differentiation through upregulation of JunB in C2C12 cells. J. Cell Physiol. 207: 428-436.

Pasarica M, Zachwieja JJ, Dejonge L, Redman S, et al. (2007). Effect of growth hormone on body composition and visceral adiposity in middle-aged men with visceral obesity. J. Clin. Endocrinol. Metab. 92: 4265-4270.

Paul C, Seiliez I, Thissen JP and Le CA (2000). Regulation of expression of the rat SOCS-3 gene in hepatocytes by growth hormone, interleukin-6 and glucocorticoids mRNA analysis and promoter characterization. Eur. J. Biochem. 267: $5849-5857$.

Plockinger U and Reuter T (2008). Pegvisomant increases intra-abdominal fat in patients with acromegaly: a pilot study. Eur. J. Endocrinol. 158: 467-471.

Rico-Bautista E, Negrin-Martinez C, Novoa-Mogollon J, Fernandez-Perez L, et al. (2004). Downregulation of the growth hormone-induced Janus kinase 2/signal transducer and activator of transcription 5 signaling pathway requires an intact actin cytoskeleton. Exp. Cell Res. 294: 269-280.

Stewart WC, Baugh JE Jr, Floyd ZE and Stephens JM (2004). STAT 5 activators can replace the requirement of FBS in the adipogenesis of 3T3-L1 cells. Biochem. Biophys. Res. Commun. 324: 355-359.

Sun C, Wang L, Yan J and Liu S (2012a). Calcium ameliorates obesity induced by high-fat diet and its potential correlation with p38 MAPK pathway. Mol. Biol. Rep. 39: 1755-1763.

Sun C, Qi R, Wang L, Yan J, et al. (2012b). p38 MAPK regulates calcium signal-mediated lipid accumulation through changing VDR expression in primary preadipocytes of mice. Mol. Biol. Rep. 39: 3179-3184.

Tollet-Egnell P, Flores-Morales A, Stavreus-Evers A, Sahlin L, et al. (1999). Growth hormone regulation of SOCS-2, SOCS-3, and CIS messenger ribonucleic acid expression in the rat. Endocrinology 140: 3693-3704.

Turnley AM (2005). Role of SOCS2 in growth hormone actions. Trends Endocrinol. Metab. 16: 53-58.

Zhang Y, Zhao J, Zhang H, Gai Y, et al. (2010). The involvement of suppressors of cytokine signaling 2 (SOCS2) in immune defense responses of Chinese mitten crab Eriocheir sinensis. Dev. Comp. Immunol. 34: 42-48. 